\title{
Análise de indicadores internos e externos relevantes à resolutividade diagnóstica em laboratório de referência em imuno-histoquimica
}

\author{
Analysis of internal and external factors potentially relevant to the diagnosis in \\ immunohistochemistry in a public reference laboratory
}

Suely Nonogaki'; Cristina Takami Kanamura'; Luciana França de Oliveira²; Mônica Conte Belaª ; Yara de Menezes; Alda Wakamatsu ${ }^{4}$; Raimunda Telma de Macedo Santos ${ }^{1}$; Venâncio Avancini Ferreira Alves ${ }^{5}$

\section{unitermos \\ Imuno-histoquímica}

Resolutividade

Comunicação

\section{resumo}

Objetivo: Avaliar a resolutividade da imuno-histoquímica (IHQ) no diagnóstico de neoplasias em um laboratório de referência da rede de saúde pública e determinar potenciais influências da comunicação entre a fonte requisitante e o laboratório executante sobre tal resolutividade. Material e métodos: Mil casos oncológicos oriundos de oito hospitais públicos foram submetidos a exame IHQ, sendo 500 imediatamente anteriores e 500 posteriores à intervenção para aprimoramento da comunicação entre os requisitantes e o laboratório de IHQ. A recuperação de antígenos foi realizada pelo calor úmido sob pressão, e o sistema de detecção foi o LSAB plus System. Os resultados foram expressos como positivo, negativo ou inconclusivo. Foram coletadas informações sobre recebimento do bloco de parafina e fixador utilizado, guia de requisição de serviços de diagnóstico e terapia (SADT), laudo anatomopatológico original, topografia, idade e sexo do paciente. Resultados e conclusão: Foram coradas 5.719 lâminas pela IHQ de 989 casos considerados. A IHQ mostrou-se resolutiva em 919/989 (92,9\%) casos. O número de antígenos por caso variou de um a 22, com média de 5,8 marcadores. A pesquisa de até cinco antígenos resolveu 534 casos e foram necessários até 10 marcadores para esclarecer 919 casos. Ainda hoje, informações básicas, como laudo anatomopatológico, idade e sexo do paciente, topografia, hipótese diagnóstica precisamente exposta, fixador e blocos de parafina em boas condições nem sempre são disponibilizadas aos laboratórios de referência. $\mathrm{O}$ aprimoramento dessa comunicação é essencial para a racionalização do fluxo dos exames IHQ e o incremento na qualidade da conclusão diagnóstica.

Objectives: The aim of this study was to evaluate the resolutivity of immunohistochemical (IHC) assays on neoplastic samples in a public health laboratory and to assess the influence of communication between the requiring institution and reference one on the quality of the IHC diagnosis. Material and methods: One thousand oncological samples from eight public hospitals were submitted to IHC assay: 500 immediately before and 500 after an intervention demanding further information from the requiring pathologist. Antigen retrieval was performed in a pressure cooker and the detection system was LSAB plus System. The results were expressed as positive, negative or inconclusive. Information about paraffin blocks, fixatives, official requiring form, the attachment of original anatomopathological report, topography of the lesion, age and gender of the patients was collected. Results and conclusion: From 989 samples, 5,719 slides were stained by IHC, leading to a resolutivity for $919 / 989$ (92.9\%). The number of antigen tested ranged from one to 22 - average of 5.8 for case. Panels with up to five antigens per case resolved 534 samples, whereas up to 10 markers were necessary to resolve 919 samples. Even nowadays, basic information, such as anatomopathological reports, age, gender, representative and technically superior paraffin block are not always available to the reference laboratory. The improvement of such communication is essential to rationalize the flux of immunohistochemical tests and to enhance the quality of diagnostic conclusions.

1. Pesquisadoras científicas do Laboratório de Imuno-histoquímica da Divisão de Patologia do Instituto Adolfo Lutz (IAL).

2. Estagiárias do Programa de Aprimoramento em Imuno-histoquímica da Fundação do Desenvolvimento Administrativo (FUNDAP) na Divisão de Patologia do IAL.

3. Médica patologista da Divisão de Patologia do IAL;

4. Pesquisadora do Laboratório de Investigação em Patologia Hepática (LIM 14) da Faculdade de Medicina da Universidade de São Paulo (FMUSP)

5. Professor titular do Departamento de Patologia do LIM 14; diretor da Divisão de Anatomia Patológica do Hospital das Clínicas da FMUSP.

Trabalho realizado no Laboratório de Imuno-histoquímica da Divisão de Patologia do IAL e no LIM 14 da FMUSP. 


\section{Introdução}

A busca da qualidade do atendimento do serviço médico-laboratorial ao paciente é motivo de contínuos esforços, e a gerência da qualidade em histologia e imuno-histoquímica (IHQ) acompanha essa evolução.

O laboratório de IHQ da Divisão de Patologia do Instituto Adolfo Lutz (IAL) tem atuado como centro de referência da rede pública no estudo de neoplasias e doenças infecciosas desde a sua criação, em 1981, com as pioneiras produção e caracterização IHQ de anticorpos anti-HBs em tecido hepático(1), até o presente, quando os casos atendidos em consultoria já superam 34 mil.

Nesses 25 anos, a IHQ experimentou progressiva evolução, com a introdução de métodos de amplificação de sinal mais sensíveis e sobretudo com os sistemas de "recuperação de antígenos" (RA), que tornaram possível a identificação de grande variedade de antígenos ${ }^{(4,16)}$ em amostras fixadas em formol. Hoje são utilizados diferentes métodos de RA baseados em calor, com destaque para vapor úmido (panela de pressão, panela a vapor,

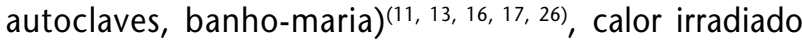
(microondas) $^{(4-6,9,16,17)}$, combinação de calor úmido e irradiado (panela de pressão em microondas) ${ }^{(23)}$ ou digestão enzimática com calor úmido ou irradiado ${ }^{(4,5,13,21)}$.

Nesse período, foram também introduzidos novos anticorpos monoclonais, bem como sistemas de amplificação mais sensíveis, como o complexo biotinil-tiramida( ${ }^{(3,18)}$, polímeros de dextrana ${ }^{(3,18)}$ e novas opções aos já tradicionais complexos avidina-biotina-HRP $(A B C)^{(8)}$ e estreptavidinabiotina-HRP (StreptABC) ${ }^{(7)}$.

Swanson ${ }^{(19)}$, em 1993, apresentou sua preocupação com a maior limitação do método $\mathrm{IHQ}$ - a preservação dos tecidos -, cuja possibilidade de danos aos antígenos teria como conseqüência alterações de sensibilidade e especificidade da interação antígeno/anticorpo. Nicholson e Leake ${ }^{(12)}$ alertaram para a necessidade de estabelecer acesso apropriado ao controle externo de qualidade, visando minimizar a variabilidade nos protocolos dos laboratórios quanto a coleta, processamento e cortes de tecidos fixados em formalina e incluídos em parafina. Concluíram que tais fatores poderiam interferir no resultado dos ensaios $\mathrm{IHQ}$, com possivel interferência sobre o limiar da semiquantificação, acarretando diagnósticos inadequados e, em última análise, seleção inadequada do procedimento terapêutico.

Conquanto feliz pelo treinamento de mais de 400 profissionais especializados, a equipe do IAL tem destacado a importância de desenvolvimento e aplicação de cuidados para garantia de qualidade nos mais de 200 laboratórios de IHQ atuando no Brasil. Em 1999, no Manual de imunohistoquímica da Sociedade Brasileira de Patologia (SBP), Alves $^{(2)}$ demonstrou preocupação com o gerenciamento da qualidade em IHQ. Para tal, discutiu a busca de instrumentos de avaliação, visando otimização dos resultados, e sugeriu como principais pontos para a garantia da qualidade: as corretas indicação e seleção do painel de anticorpos, o protocolo de reações e a interpretação das lâminas coradas pelo patologista.

Segundo Vyberg et al. ${ }^{(24)}$, os resultados da IHQ dependem de fatores pré-analíticos (fixação, processamento de tecidos), analíticos (métodos de reações) e pós-analíticos (interpretação dos resultados). Uma vez otimizados todos os fatores laboratoriais analíticos e pós-analíticos, a gestão da qualidade passa a centrar sua atenção nos fatores pré-analíticos.

\section{Objetivo}

Considerando os avanços técnicos e as novas indicações, o presente estudo foi delineado para avaliar a resolutividade da IHQ no diagnóstico de neoplasias em um laboratório de referência da rede de saúde pública, bem como determinar potenciais influências da comunicação entre a fonte requisitante e o laboratório executante sobre tal resolutividade.

\section{Material e método}

Dos 5.865 exames seqüenciais realizados no laboratório de IHQ do IAL, entre maio de 2001 e julho de 2004, foram selecionados mil casos de natureza oncológica oriundos dos seguintes hospitais da rede pública:

- Hospital Estadual Mário Covas (Hospital Estadual do $A B C$ ), em Santo André (SP);

- Hospital Municipal Dr. Cármino Caricchio, em São Paulo (SP);

- Hospital Heliópolis, em São Paulo (SP);

- Conjunto Hospitalar do Mandaqui, em São Paulo (SP);

- Hospital Nossa Senhora da Conceição, em Porto Alegre (RS);

- Hospital Infantil Nossa Senhora da Glória, em Vitória (ES);

- Hospital Geral de Vila Penteado, em São Paulo (SP).

Uma das metas do presente estudo foi a avaliação do impacto da padronização dos critérios formais para recebimento das amostras referentes aos casos consultados. Após 500 casos nas condições de comunicação então vigente, visando o aprimoramento da comunicação entre os requisitantes e o laboratório de referência, foi enviada correspondência 
solicitando para todos os casos: cópia do laudo anatomopatológico, guia de requisição de serviços de diagnóstico e terapia (SADT), requisição médica do exame IHQ contendo informações sobre o paciente, hipóteses diagnósticas clínicas e morfológicas, garantindo-se o adequado envio de blocos de parafina ou lâminas de citologia e informação para a devolução do resultado.

Todos os blocos e/ou lâminas recebidos foram registrados, sendo preparadas lâminas com novos cortes histológicos, corados por hematoxilina e eosina (HE) e posteriormente examinados pelos médicos patologistas ( $\mathrm{YM} \mathrm{e}$ VAFA) para seleção do painel inicial de anticorpos que, para otimizar custos, foi sempre o mais restrito possível. Quando necessário, foram realizadas reações imuno-histoquímicas adicionais, com seleção de mais marcadores baseados nos resultados da reação anterior.

Devido à indisponibilidade de lâminas em branco ou blocos de parafina, em cinco casos foi apenas possível a revisão do diagnóstico histopatológico. Após microtomia e coloração pelo $\mathrm{HE}$, outros cinco casos não evidenciaram tumor representativo na amostra residual, e em um caso foi recebido o bloco errado. Tais amostras foram consideradas inadequadas para IHQ, sendo, portanto realizadas reações, conforme citado por Santos et al. ${ }^{(14)}$ em 989 casos, compondo um total de 5.719 lâminas. Vale salientar que em 5.143 (90\%) destas foi necessária a recuperação de antígenos, que foi obtida por calor úmido e pressão com solução de ácido cítrico $10 \mathrm{mM} \mathrm{pH} \mathrm{6,0.} \mathrm{A} \mathrm{atividade} \mathrm{da} \mathrm{peroxidase}$ endógena foi bloqueada com água oxigenada 20 volumes. Os anticorpos primários, previamente titulados para as condições deste laboratório, foram diluídos no momento do uso em solução salina tamponada com sais de fosfato (PBS) contendo soroalbumina bovina a $1 \%$ com azida sódica a $0,1 \%$, para bloqueio de ligações inespecíficas. As lâminas foram incubadas por 30 minutos a $37^{\circ} \mathrm{C}$ e, em seguida, por 18 a 20 horas a $5^{\circ} \mathrm{C}$. O sistema de detecção escolhido foi o LSAB plus System (Dako Cytomation ${ }^{\circledR}$, EUA) marcado com peroxidase; a revelação foi feita com diaminobenzidina $\left(\right.$ Sigma $\left.^{\circledR}, E U A\right)$ e a contracoloração, por hematoxilina de Harris. Todas as reações foram realizadas acompanhadas de seus respectivos controles, e os resultados obtidos foram expressos como: "positivo", "negativo", "inconclusivo" ou "material inadequado" após realização de reação IHQ.

\section{Resultados}

A análise das informações enviadas pelas instituições requisitantes de mil casos selecionados demonstrou que:
- 536 casos foram acompanhados da guia SADT, viabilizando o preparo de relatórios para o Sistema Único de Saúde (SUS);

- 462 casos vieram acompanhados do laudo anatomopatológico original;

- 890 casos continham informes sobre a idade e 965 sobre o gênero do paciente, sendo $431(44,7 \%)$ do sexo feminino e $534(55,3 \%)$ do masculino.

Quanto ao fixador utilizado, 657 casos tinham relato do uso de formalina; 20 casos, de Bouin; 3 casos, de álcool; não havendo informe sobre o tipo de fixador em 320 casos.

Em 909 casos foi recebido um bloco de parafina; em 58 casos, dois blocos; em 10 casos, três blocos; em 11 casos, quatro blocos; em quatro casos, cinco blocos e em dois casos, seis blocos de parafina. Em dois casos foram recebidas apenas lâminas em branco, e em três casos não foram recebidos blocos ou lâminas em branco. Em um caso foi enviado bloco não correspondente a neoplasia, tornando necessário novo procedimento de envio.

A topografia das amostras tumorais foi coletada em 990 casos, classificados a partir da Classificação Internacional de Doenças para Oncologia (CID-O), 3ae edição. A distribuição topográfica dos casos recebidos em consultoria é apresentada na Tabela 1, destacando-se o grande número de neoplasias em linfonodos. De outra parte, os casos de mama visaram o diagnóstico diferencial, já que a análise da imunoexpressão de receptores hormonais com vistas à seleção terapêutica não faz parte das ações desse laboratório.

A intervenção para o aprimoramento na comunicação entre os médicos requisitantes e o laboratório de referência teve impacto positivo nos informes pré-analíticos, conforme exposto na Tabela 2. Diversas informações técnicas relevantes foram acrescidas com o incremento do envio do laudo anatomopatológico de $33,2 \%$ para $59,2 \%$, sendo o cadastro do caso no SUS mais bem efetivado com o recebimento da guia SADT, que passou de $13 \%$ para $94,2 \%$.

Com relação a aspectos intralaboratoriais, para o esclarecimento dos 989 casos considerados adequados à realização de reações $\mathrm{IHQ}$, empregamos 120 anticorpos distintos nos painéis diagnósticos. Os 15 marcadores mais utilizados em nossos painéis estão listados na Tabela 3. Para o diagnóstico diferencial entre neoplasias morfologicamente pouco diferenciadas, fica evidente a importância de marcadores de linhagens celulares, especialmente os antígenos de células linfóides e as citoqueratinas.

A Tabela 4 mostra que a IHQ foi resolutiva em 919 casos $(919 / 989=92,9 \%)$, confirmando a hipótese diagnóstica con- 


\section{Tabela 1 Topografia das amostras recebidas}

\begin{tabular}{lc}
\hline Topografia & Freqüência \\
Linfonodos & 207 \\
Coração, mediastino e pleura & 70 \\
Pele & 65 \\
Brônquios e pulmões & 64 \\
Encéfalo (SNC) & 62 \\
Sistema hematopoiético & 52 \\
Estômago & 36 \\
Tecidos conjuntivo, subcutâneo e outros tecidos moles & 32 \\
Fígado e vias biliares intra-hepáticas & 27 \\
Retroperitônio e peritônio & 27 \\
Ossos, articulações e cartilagens articulares & 23 \\
Ovário & 19 \\
Mama & 18 \\
Outras localizações & 188 \\
Localização mal definida & 100 \\
Localização primária não referida & 10 \\
Total & 1.000 \\
\hline
\end{tabular}

\section{Tabela 2 comunicação}

\begin{tabular}{lcc}
\hline Indicadores & Antes & Depois \\
Guia SADT & $65 / 500(13 \%)$ & $471 / 500(94,2 \%)$ \\
Laudo anatomopatológico & $166 / 500(33,2 \%)$ & $296 / 500(59,2 \%)$ \\
Idade do paciente & $435 / 500(87 \%)$ & $455 / 500(91 \%)$ \\
Gênero do paciente & $470 / 500(94 \%)$ & $495 / 500(99 \%)$ \\
Fixador utilizado & $313 / 500(62,6 \%)$ & $344 / 500(68,8 \%)$ \\
Topografia & $493 / 500(98,6 \%)$ & $497 / 500(99,4 \%)$ \\
\hline
\end{tabular}

\section{Tabela 3 Quinze anticorpos mais utilizados em ordem decrescente}

\begin{tabular}{lcc}
\hline Antígeno-alvo & Clones & Fabricante \\
CD20 & L26 & Dako \\
CD3 & Policlonal & Dako \\
Pancitoqueratinas & AE1AE3 & Dako \\
Proteína S-100 & Policlonal & Dako \\
CD30 & BerH2 & Dako \\
Citoqueratinas 8 e 18 & CAM5.2 & Becton Dickinson \\
Citoqueratinas alto peso molecular & 34 E12 & Dako \\
Cromogranina A & LK2H10 & Dako \\
CD34 & QBEnd 10 & Dako \\
Vimentina & V9 & Dako \\
EMA & E29 & Dako \\
Citoqueratina 7 & OVTL12-20 & Dako \\
CD15 & C3-1 & Dako \\
Actina de músculo liso & IA4 & Dako \\
Citoqueratina 20 & ITKs20 & Dako \\
\hline
\end{tabular}


siderada mais provável pelo requisitante em 170 casos $(17,2 \%)$ e trazendo conclusão discordante da hipótese morfológica em 176 (17,8\%). Destaca-se especialmente a contribuição do estudo IHQ em outros 573 casos $(57,9 \%)$, nos quais foi possível a conclusão do diagnóstico mesmo diante de um quadro morfológico considerado inconclusivo/indiferenciado pelos médicos requisitantes. De outra parte, 16 casos foram considerados inconclusivos (1,6\%), $14(1,4 \%)$ apresentaram material inadequado para análise após coloração IHQ e em 40 (4\%) a IHQ não ajudou no diagnóstico.

\section{№ de reações realizadas $x$ resolutividade}

O conjunto de reações IHQ necessárias para o estudo desses 989 casos considerados adequados para a reação compôs um total de 5.719 antígenos pesquisados, variando de um a 22, com média de 5,8 marcadores por caso.

A pesquisa de até cinco antígenos resolveu 534/989 (54\%) casos, entretanto foram necessários até 10 marcadores para a resolução do total de 919/989 $(92,9 \%)$ casos.

Em 41 casos, foram estudados simultaneamente agentes infecciosos associados a marcadores de neoplasia, sendo a associação mais freqüente a pesquisa do vírus Epstein-Barr (25 casos).

Uma questão relevante no diagnóstico IHQ é o número de reações efetuadas. A adoção da estratégia de "painéis iniciais mínimos" propicia economia de custos de reagentes, mas acarreta maiores números de reações necessárias para atingir o diagnóstico. Nesta casuística, 622 casos $(62,9 \%)$ tiveram diagnóstico conclusivo já na primeira reação; 300 casos (30,3\%) tiveram necessidade de ampliação do painel de marcadores em segunda (231) e terceira reação (69); e 33 casos tiveram mais de quatro reações. Já as questões técnicas tornaram necessária a repetição de reações em 34 casos (3,4\%).

A Tabela 5 apresenta os diagnósticos mais freqüentemente encontrados neste estudo.

\section{Pesquisa de sítio primário}

A presente casuística inclui um conjunto de 135 casos em que a demanda referia-se à busca do sítio primário de carcinomas, sendo $67(49,6 \%)$ adenocarcinomas; nove $(6,7 \%)$ carcinomas pouco diferenciados; nove carcinomas indiferenciados $(6,7 \%)$ e seis carcinomas neuroendócrinos (4,5\%); cinco carcinomas epidermóides (3,7\%) e 39 casos de outros tipos histológicos. Entre estes, 125 casos (92,6\%) tiveram resultados conclusivos. Os sítios primários mais freqüentemente encontrados neste estudo foram: pulmão (35), mama (10), ovário (9), próstata (7) e vias biliopancreáticas (7).

\section{Tabela 4 Resolutividade do exame IHQ}

\begin{tabular}{lccc}
\hline Resultados & Revisão pré-IHQ (HE) & Pós-reação IHQ & Total \\
Confirmação da hipótese original & 0 & $170(17,2 \%)$ & 170 \\
Discordância da hipótese original & 3 & $176(17,8 \%)$ & 179 \\
Esclarecimento de casos sem hipóteses & 1 & $573(57,9 \%)$ & 574 \\
Total de casos resolvidos & 4 & $919(92,9 \%)$ & 923 \\
Perfil IHQ inconclusivo & 0 & $16(1,6 \%)$ & 16 \\
Análise IHQ não-contribuitória & 0 & $40(4 \%)$ & 40 \\
Material inadequado pré-IHQ & 7 & 0 & 7 \\
Material inadequado pós-IHQ & 0 & $14(1,4 \%)$ & 14 \\
Total geral & 11 & 989 & 1.000 \\
\hline
\end{tabular}

\section{Tabela 5 Diagnósticos mais freqüentes}

\section{Diagnósticos}

Carcinoma indiferenciado/pouco diferenciado

Carcinoma neuroendócrino/tumor carcinóide

Adenocarcinoma

Carcinoma epidermóide

Outros carcinomas

Neoplasias malignas indiferenciadas
Total de casos

68

56

89

35

47

12 
Melanoma 21

Mesotelioma

Linfoma Hodgkin

Linfoma não-Hodgkin linfócitos B

Linfoma não-Hodgkin linfócitos T

Outros linfomas

Plasmocitoma

Hiperplasia linfóide reacional $\quad 50$

Processo inflamatório 9

Leiomiossarcoma $\quad 16$

Rabdomiossarcoma $\quad 8$

Fibrossarcoma

Fibroistiocitoma

Angiossarcoma 3

Hemangioendotelioma $\quad 1$

Lipossarcoma $\quad 7$

Neurofibrossarcoma

Outros sarcomas 16

Dermatofibroma

Dermatofibrossarcoma protuberans 3

GIST 13

PNET

Astrocitoma 9

Glioblastoma

Tumores de células germinativas $\quad 12$

Tumor de Wilms 6

$\begin{array}{ll}\text { Adenoma hipofisário } & 19\end{array}$

Fibroadenoma mamário 19

Outros diagnósticos 122

$\begin{array}{ll}\text { Total parcial } & 919\end{array}$

Análise IHQ não-contribuitória $\quad 40$

Perfil IHQ inconclusivo 16

Material inadequado após IHQ $\quad 14$

Total parcial com reação IHQ $\quad 989$

Material inadequado pelo HE deste serviço $\quad 7$

Revisão com HE externo 4

$\begin{array}{ll}\text { Total geral } & 1.000\end{array}$

GIST: tumor gastrointestinal estromal; PNET: tumor neuroectodérmico primitivo.

\section{Discussão}

As últimas três décadas testemunharam a grande contribuição da IHQ ao diagnóstico morfológico, especialmente em casos de neoplasias pouco diferenciadas e na seleção de possíveis sítios de origem de metástases. Para que essa contribuição continue crescente, além do rigoroso controle da qualidade de cada etapa das reações, a análise crítica da comunicação entre as instituições requisitantes e os laboratórios de referência é um dos instrumentos que julgamos mais importantes para a implantação de medidas que afe- tem positivamente as etapas pré e pós-analítica do conjunto de procedimentos, resultando no máximo aprimoramento ao diagnóstico final.

Além de demonstrar a elevada resolutividade de exame IHQ (92,9\%), o presente estudo aborda a importância dos fatores pré-analíticos, destacando o impacto positivo de intervenção para aprimoramento da comunicação entre os médicos requisitantes e o laboratório de IHQ.

Após tal intervenção, o grande incremento no recebimento da guia SADT permitiu a oficialização do atendimen- 
to pelo SUS. Alguns parâmetros já se encontravam em bom índice, como informações sobre sexo, idade e topografia da lesão. Informações técnicas, como o uso do fixador e a cópia do laudo anatomopatológico, continuam aquém do desejado. A maior disponibilidade dessas informações confere aos laudos conformidade com o padrão proposto pela Association of Directors of Anatomic and Surgical Pathology (ADASP), com as modificações sugeridas por Taylor ${ }^{(21)}$ contendo informes sobre o paciente (idade, sexo), hipótese diagnóstica inicial, espécime (localização topográfica), natureza do espécime analisado (fixador, cortes de parafina, citológicos etc.), além de informações sobre os Acs e clones aplicados ao caso, sistema de amplificação utilizado, das leituras (positivo/negativo/inconclusivo) com detalhes dos achados (poucas células coradas, positividade focal etc.), bem como o diagnóstico.

Entre os indicadores externos, o envio do laudo anatomopatológico nos pareceu ser de fundamental importância. A análise dos casos inconclusivos (16/989) revelou que em 12/16 (75\%) a requisição não estava acompanhada do laudo anatomopatológico.

A qualidade do material recebido pode comprometer o resultado final do exame IHQ, preocupação já citada por Nicholson e Leake em 2000 (12). Mesmo se tratando de um laboratório cujos casos são todos oriundos de outras instituições, o índice de inadequação quanto ao material para a presente casuística (2\%) permanece em níveis aceitáveis.

Entre os indicadores internos, o presente estudo aponta para a necessidade de seleção de um painel inicial relativamente amplo, já que a tentativa de excessiva economia implicou em aumento no número de reações a serem realizadas e, conseqüentemente, no prazo de dias para entrega do laudo conclusivo. A maior facilidade de obtenção de reagentes, a nosso ver, poderá trazer considerável economia na análise global do atendimento ao paciente, devendo tal informe merecer análise mais cuidadosa pelos especialistas em economia da saúde.

O grau de resolutividade aqui obtido em condições habituais da rede pública do SUS (92,9\%) é similar ao referido por Werner et al. ${ }^{(25)}$, Schmitt et al. ${ }^{(15)}$ e Torres et al. ${ }^{(23)}$. Em todos esses estudos fica evidente a enorme contribuição diagnóstica dos exames IHQ, cujo grau de conclusividade variou de $83 \%$ a $94 \%$.

O presente estudo organiza ainda a lista dos 15 anticorpos mais indicados para o diagnóstico de neoplasias pouco diferenciadas e para a busca de prováveis sítios primários, com semelhanças aos citados por Maxwell e McClugga$\mathrm{ge}^{(10)}$. A nosso ver, esses anticorpos devem constar de um conjunto mínimo de reagentes continuamente disponíveis em laboratórios de IHQ diagnóstica, podendo ser este um informe útil para os auditores especializados.

Um informe final diz respeito à análise do número de marcadores usados na resolução de um caso: verificamos que nas condições da economia máxima a que nos propusemos, com até cinco marcadores, apenas 54\% dos casos são esclarecidos. O número médio de anticorpos neste estudo foi de 5,8; salientando-se que para atingirmos $85 \%$ seriam necessários oito. Para um laboratório de IHQ como o do IAL, que recebe consultas de vários hospitais da rede pública, a restrição do pagamento de até quatro marcadores impossibilitaria o esclarecimento diagnóstico de mais de $60 \%$ dos casos recebidos.

Em suma, esta análise do desempenho da IHQ de mil casos oncológicos recentemente recebidos no IAL, laboratório de referência da Secretaria de Saúde do Estado de São Paulo, demonstra resolutividade de $92,9 \%$, contribuindo tanto na caracterização de linhagens celulares como na sugestão de possíveis sítios de origem de metástases. A partir dos dados observados em nosso estudo, apontamos diversos indicadores úteis para os auditores de qualidade. Avanços ainda maiores poderão ser obtidos com medidas muito simples, incluindo contínuo aprimoramento da comunicação com os colegas requisitantes de exame e maior investimento em reagentes, permitindo que os painéis iniciais possam ser mais abrangentes.

\section{Agradecimentos}

Agradecemos aos médicos das instituições citadas, que enviaram os casos para consultoria em imuno-histoquímica, e ao Dr Humberto Torloni, do Hospital A. C. Camargo, São Paulo, pela antecipação da 3 a edição do CID-O.

\section{Referências}

1. ALVES, V.A. et al. Utilização da técnica de anticorpos não marcados peroxidase (PAP) na detecção do antígeno de superfície da hepatite $\mathrm{B}$ em tecido hepático. Rev Inst Adolfo Lutz, v. 40, p. 101-6, 1980.
2. ALVES, V.A. Garantia de qualidade em imuno-histoquímica. In: ALVES, V.A.; BACCHI, C.E.; VASSALLO, J. Manual de imuno-histoquímica. São Paulo: Sociedade Brasileira de Patologia, 1999. Cap. 1; p. 1-7. 
3. BUNEA, M.; ZARNESCU, O. New current aspects on the immunohistochemical techniques. Roum Biotechnol Lett, v. 6, n. 3, p. 177-206, 2001.

4. CATTORETTI, G. et al. Antigen unmasking on formalin-fixed, paraffin-embedded tissue sections. J Pathol, v. 171, n. 2, p. 83-98, 1993.

5. CATTORETTI, G.; SUURMEIJER, A.J. Antigen unmasking on formalin-fixed paraffin embedded tissues using microwaves: a review. Adv Anat Pathol, v. 2, n. 1, p. 2-9, 1995.

6. GOWN, A.M.; WEVER, N.; BATTIFORA, H. Microwavebased antigenic unmasking: a revolutionary new technique for routine immunohistochemistry. Appl Immunohistochem, v. 1, n. 4, p. 256-66, 1993.

7. GUESDON, J.L.; TERNYNCK, T.; AVRAMEAS, S. The use of avidin-biotin interaction in immunoenzymatic techniques. J Histochem Cytochem, v. 27, n. 8, p. 1131-9, 1979.

8. HSU, S.M.; RAINE, L; FANGER, H. Use of avidin-biotinperoxidase complex $(A B C)$ in immunoperoxidase techniques: a comparison between $\mathrm{ABC}$ and unlabeled antibody (PAP) procedure. J Histochem Cytochem, v. 29, n. 4, p. 577-80, 1981

9. LEONG, A.S.; MILIOS, J. An assessment of the efficacy of the microwave antigen-retrieval procedure on a range of tissue antigens. Appl Immunohistochem, v. 1, n. 4, p. 267-74, 1993.

10. MAXWELL, P.; McCLUGGAGE, W.G. Audit and internal quality control in immunohistochemistry. J Clin Pathol, v. 53, n. 12, p. 929-32, 2000.

11. MILLER, K. et al. Antigen unmasking in formalin-fixed routinely processed paraffin wax-embedded sections by pressure cooking: a comparison with microwave oven heating and traditional methods. Adv Anat Pathol, v. 2, p. 60-4, 1995

12. NICHOLSON, R.I.; LEAKE, R. Quality control for the immunohistochemical demonstration of oestrogen and progesterone receptors. J Clin Pathol, v. 53, n. 4, p. $247,2000$.

13. NORTON, A.J.; JORDAN, S.; YEOMANS, P. Brief, high temperature heat denaturation (pressure cooking): a simple and effective method of antigen retrieval for routinely processed tissues. J Pathol, v. 173, n. 4, p. 371-9, 1994

14. SANTOS, R.T. et al. Procedimentos laboratoriais em imuno-histoquímica e hibridização "in situ". In: ALVES, V.A.; BACCHI, C.E.; VASSALLO, J. Manual de imunohistoquímica. São Paulo: Sociedade Brasileira de Patologia, 1999. Cap. 21; p. 237-59.

15. SCHMITT, F.C. et al. Utilidade dos métodos imunohistoquímicos para o diagnóstico anatomopatológico. Rev Hosp Clin Fac Med S Paulo, v. 46, n. 1, p. 26-30, 1991.

16. SHI, S.R; KEY, M.B.; KALRA, KL. Antigen retrieval in formalin-fixed, paraffin-embedded tissues: an enhancement method for immunohistochemical staining based on microwave oven heating of tissue sections. J Histochem Cytochem, v. 39, n. 6, p. 741-8, 1991.

17. SHI, S.R.; COTE, R.J.; TAYLOR, C.R. Antigen retrieval immunohistochemistry: past, present and future. J Histochem Cytochem, v. 45, n. 3, p. 327-43, 1997.

18. SHI, S.R.; COTE, R.J.; TAYLOR, C.R. Antigen retrieval techniques: current perspectives. J Histoch Cytochem, v. 49, n. 8, p. 931-7, 2001.

19. SWANSON, P.E. Methodologic standardization in immunohistochemistry: a doorway opens. Appl Immunohistochem, v. 1, n. 4, p. 229-31, 1993.

20. SZEKERES, G.; AUDOUIN, J.; LÊ TOURNEAU, A. Is immunolocalization of antigen in paraffin section dependent on method of antigen retrieval? Appl Immunohistochem, v. 2, n. 2, p. 137-40, 1994.

21. TAYLOR, C.R. An exaltation of experts: concerted efforts in the standardization of immunohistochemistry. Appl Immunohistochem, v. 1, n. 4, p. 232-43, 1993.

22. TAYLOR, C.R. et al. Comparative study of antigen retrieval heating methods: microwave, microwave and pressure cooker, autoclave, and steamer. Biotech Histochem, v. 71, n. 5, p. 263-70, 1996.

23. TORRES, L.F. et al. A contribuição da imuno-histoquímica em patologia cirúrgica: experiência de 10 anos. Rev Med Paraná, v. 56, n. 2/2, p. 31-8, 1998.

24. VYBERG, M. et al. Nordic immunohistochemical quality control. Croat Med J, v. 46, n. 3, p. 368-71, 2005.

25. WERNER, B. et al. Uso prático da imuno-histoquímica em patologia cirúrgica. J Bras Patol Med Lab, v. 41, n. 5, p. 353-64, 2005.

26. ZIDAN, A. et al. Oestrogen and progesterone receptors assessment in core biopsy specimens of breast carcinoma. J Clin Pathol, v. 50, n. 1, p. 27-9, 1997. 